\title{
Fuzzy Logic Fed Novel Dual Winding Solid State Transformer based on Dual Active Bridge for Power Quality Improvement
}

\author{
Saju $\mathbf{N}^{1}$, Dr. Jegathesan $\mathbf{V}^{2}$ \\ ${ }^{1}$ Research Scholar, Karunya Institute of Technology \& Sciences, Coimbatore, India. \\ sajunarendran@yahoo.com \\ ${ }^{2}$ Associate Professor, Karunya Institute of Technology \& Sciences, Coimbatore, India
}

\begin{abstract}
Solid State Transformers (SST) are based on power electronic compoenents. They operate at very high frequency thereby possesing reduced size and volume. Their high frequency operation is realized through power conversion stages in the dual active bridge (DAB). These transformers are aimed for power quality enhnacemnt. A novel two winding SST driven by fuzzy logic is proposed in this paper. The proposed SST has been simualted and analyzed through MATLAB/Simulink. The simulation results infer that the proposed SST scheme mitigated voltage sag, swell and provided better THD thereby improving the power quality of the system.
\end{abstract}

Key words : Solid State Transformer (SST), Dual Active Bridge (DAB), Dual Windings, Voltage Sag, Swell, Total harmonic Distortion (THD)

\section{INTRODUCTION}

Transformers are used for power transfer without change in frequency. Wide range of power transmission to several kilometers of distance are made feasible with the help of transformers. Generally transformers are operated at power frequency say $50 \mathrm{~Hz}$ or $60 \mathrm{~Hz}$. Those which operate in any of these frequencies are called as conventional transformers. The problems associated with conventional transformers are size, weight and volume. When conventional transformers are employed for large distance power transmission or distribution, their size increases with increase in the capacity. This in turn increase their volume and space occupancy. Development of power electronic devices and their high frequency operations can replace the conventional transformer. Already developed a transformer based on semiconductor devices. This transformer has various power conversion stages like AC/DC and DC/AC. Soft switching is developed based DC/Dc converter for high power density applications. Soft switching is applied for high frequency and power applications. The Dual Active Bridge (DAB) based SST operating at $100 \mathrm{kHz}$ frequency is proposed. Enhanced the operation of this DAB with bidirectional power flow capability is already done [1].

Increasing the frequency reduces the size, weight and volume of the transformer was analyzed. They suggested such transformers for power distribution systems. A high frequency switched transformer was found to be economically viable as its maintenance cost was low and also it provided higher efficiency even at 50\% of loads. High frequency AC link matrix converters well suit the SST applications. The bidirectional capability of power flow and enhanced power quality of such transformers demonstrated. Optimum design of converters for SST was proposed.

Distributed generation and the concept of microgrids are upcoming since the early 2000s. A SST for grid connected photo voltaic systems are developed earlier. A three sate SST with Dual Active Bridge (DAB) and tested it for power quality issues of residential PV system are simulated. Dynamic current referred high frequency SST [2] finds well suited for isolated battery charges, and integration of distributed energy resources. The SST on power quality aspects of total harmonic distortion (THD) is examined [3], voltage sag and swell parameters. Conventional transformer was replaced by [4] wind energy system with SST. A novel compact SST with inductors was proposed [5]. AC-DC isolated multilevel inverters based SST topology was proposed [6] for traction systems. Modified DC power electronic transformer based on series connection of full-bridge converters suggested by [7] has reduced number of power electronic devices and resulted with enhanced power quality improvement [8]. All these studies revealed the necessity for a solid state transformer with dual active bridge configuration [9].

The further sections of this paper are organized as follows. Section 2 deals with the SST topology. Modified SST with dual winding transformer and DAB is discussed in Section 3. Fuzzy driven SST with DAB is detailed in Section 4. The Simulink model and the results were presented in Section 5. The proposed system and its capability to enhance power quality are briefed as conclusion in Section 6 . 
Saju N et al., International Journal of Emerging Trends in Engineering Research, 8(8), August 2020, 4097 - 4101

\section{SST TOPOLOGY}

SST is developed for power quality improvement. SST was develop in various topologies as single stage, two-stage and three-stage. The most commonly used topology is three stage topology which is depicted in Figure 1. It consist of an input rectifier stage, DC-DC Dual Active Bridge (DAB) and output inverter stage. The DAB provides DC isolation between the power conversion stages and has a transformer which operates at high frequency.

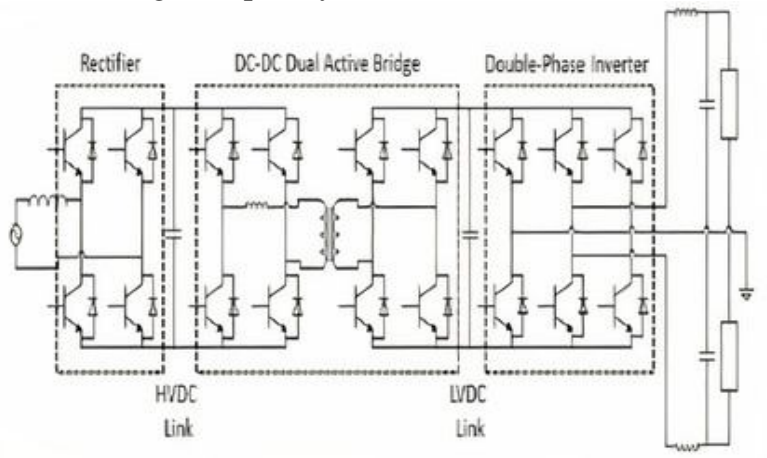

Figure 1: Three Stage Solid State Transfromer

\subsection{Conventional Three-Stage SST}

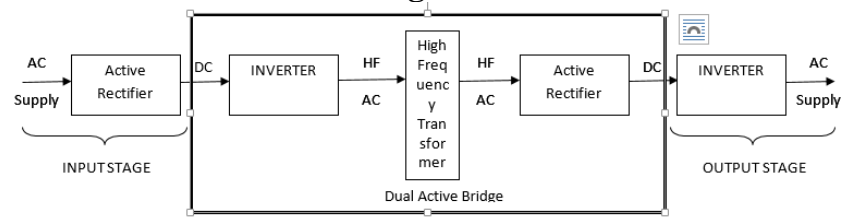

Figure 2: Conventional 3 Stage SST

The block diagram of conventional three stage SST is displayed in Figure 2. As mentioned earlier, the conventional 3 stage SST system has the input rectifier stage with active controlled rectifier. Rectified DC is converted into high frequency $\mathrm{AC}$ through the inverter. This is the first conversion of the DAB. The high frequency AC is transformed via transformer and fed to the active rectifier. Thus the output of DAB is also DC. This DC is converted to AC through inverter in the output stage and fed to the loads. Too many switching devices are employed in the system, which results in increased switching losses. It also affects the power factor and the THD of the system. To enhance the power quality improvement, a modified SST is proposed in this paper.

\section{MODIFIED SST WITH DUAL WINDING TRANSFORMER}

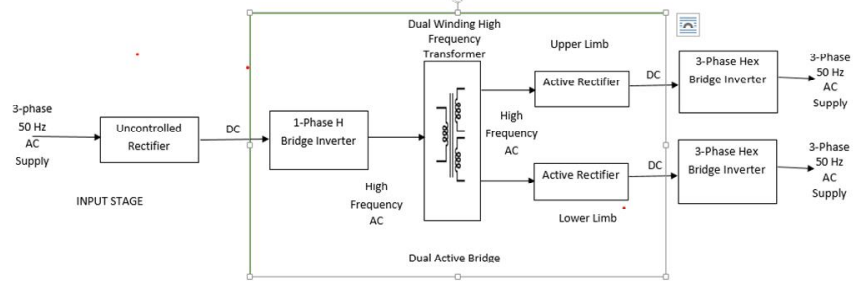

Figure 3: Modified 3 Stage SST
Figure 3 illustrates the proposed mdofied 3 stage SST. It consists of an uncontrolled rectfier in the input rectifier stage, which converts AC supply to DC. The DC is converted to AC in the signle phase $\mathrm{H}$ bridge inverter operating at freqeuncy of $25 \mathrm{kHz}$. This AC is fed to a single phase high frequency transformer whose operating frequency is $25 \mathrm{kHz}$. High frequency transformer used here has a dual winding in the seocndary. This enables the load sharing among the secondary windings. Both the upper and lower limbs of the high frequncy transformers are connected with loads through active rectifiers and three phase hex bridge inverters. The output of the hex bridge inverters are 3-phase $\mathrm{AC}$ with power frequency of $50 \mathrm{~Hz}$ or $60 \mathrm{~Hz}$, to which the loads are connected. These mdofications of the proposed thre stage SST assists the system by providing improved power quality parameters under various test condiitons. The specifications of the system are given in Table 1.

Table 1: System Specifications

\begin{tabular}{|l|l|}
\hline Input Voltage & $11 \mathrm{kV}$ \\
\hline Total Capacity & $100 \mathrm{~kW}$ \\
\hline Output Voltage & $415 \mathrm{~V}, 3$-Phase \\
\hline $\begin{array}{l}\text { Operating frequency of } \\
\text { transformer }\end{array}$ & $25 \mathrm{kHz}$ \\
\hline $\begin{array}{l}\text { Minimum loads connected in } \\
\text { secondary }\end{array}$ & $\begin{array}{l}\text { Total } 50 \mathrm{~kW}(25 \mathrm{~kW} \text { each in } \\
\text { upper and lower limbs })\end{array}$ \\
\hline
\end{tabular}

\section{FUZZY LOGIC FED MODIFIED SST}

In the proposed modified 3-stage DAB based SST system, fuzzy technique has been applied to drive the single-phase $\mathrm{H}$ bridge inverter. According to the load variations, the switching frequency of the system is varied, there by the voltage remains stable. The fuzzy logic approach aimed here is a mamdani fuzzy model. The voltage error and change in voltage error are measured from both the upper and lower limbs and are taken as input to the fuzzy system. Desired change in the frequency is the output obtained from the fuzzy block. This in turn drives the single phase $\mathrm{H}$ bridge inverter and operates it at the required frequency, thereby enhancing the voltage level. Triangular membership functions are used to define the input and output of the fuzzy rule base. The fuzzy rule based formed from the membership functions are shown in Table 2. The input and output membership functions are depicted in Figure 4. The membership functions are defined as Very Small (VS), Small (S), Medium (M), Big (B) and Very Big (VB).

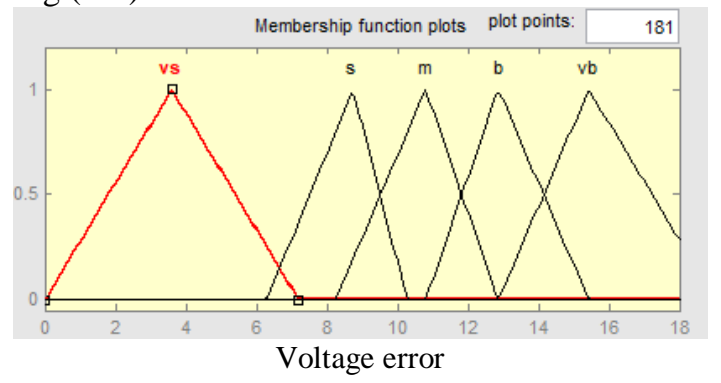




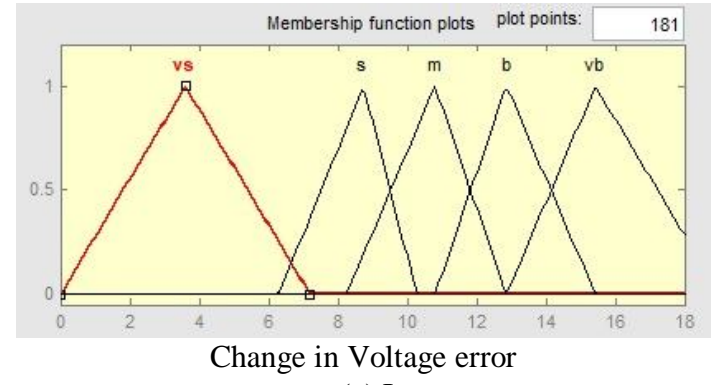

(a) Input

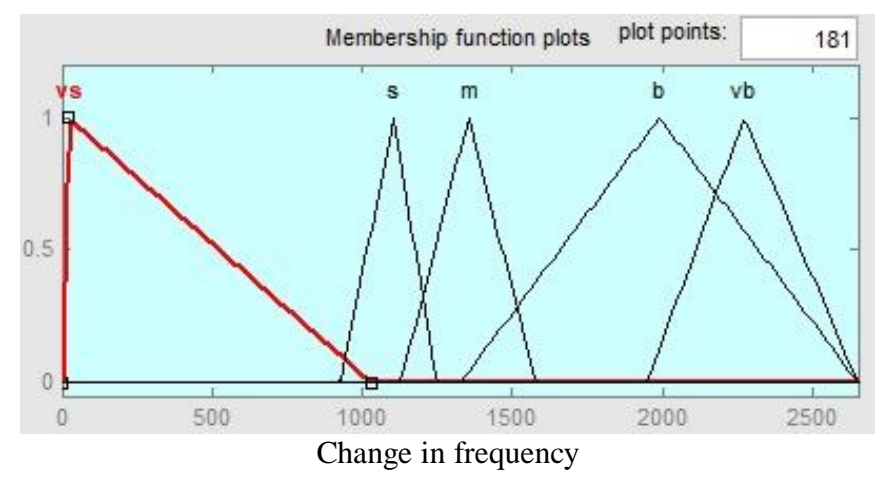

(b) Output

Figure 4: Fuzzy Membership Functions

Table 2: Fuzzy Rules

\begin{tabular}{|c|c|c|}
\hline \multicolumn{2}{|c|}{ Input Function } & \multicolumn{1}{c|}{ Output Function } \\
\hline Voltage Error & $\begin{array}{l}\text { Change in Voltage } \\
\text { Error }\end{array}$ & $\begin{array}{l}\text { Change in } \\
\text { Frequency }\end{array}$ \\
\hline VS & VS & VS \\
\hline S & S & S \\
\hline M & M & M \\
\hline B & B & B \\
\hline VB & VB & VB \\
\hline
\end{tabular}

Based on the rules formed from Table 2, the change in frequency is determined. This is the frequency at which the single phase inverter in the input side of $\mathrm{DAB}$ is to be switched.

\section{SIMULATION MODEL}

The simulation model of the proposed modified system is shown in figure 5. The proposed Fuzzy Logic based system is simulated at various load conditions. The base switching frequency is $25 \mathrm{kHz}$. Loads of $25 \mathrm{~kW}$ each are connected in the upper and lower limbs of the secondary of the transformer. Additional loads are connected to the system and based on them the power quality parameters viz. voltage sag, swell and THD are measured.

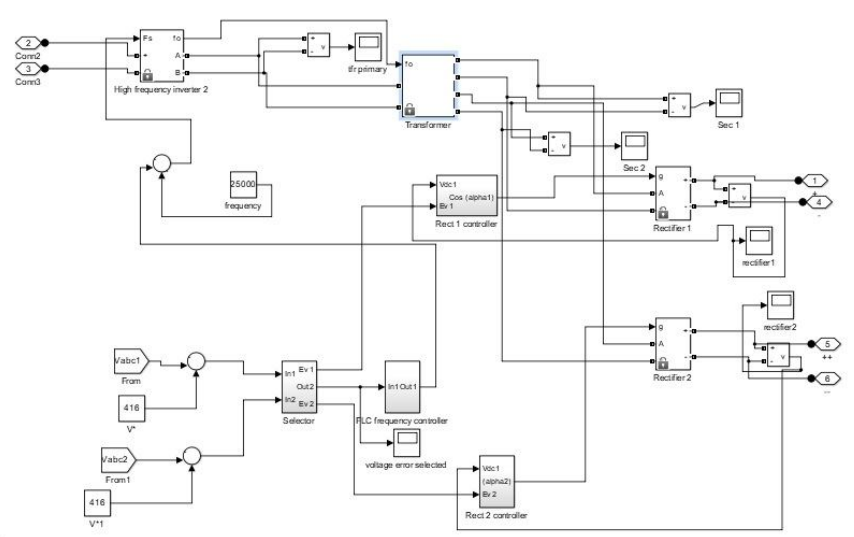

Figure 5: Simulation Model

The output voltages of both the limbs are measured and error is generated with the reference. When the load is increased, the load voltage gets reduced. This causes voltage sag. Accordingly the input frequency is increased so the output voltage increases. There by the voltage sag is mitigated. When there is a sudden decrease in the load, voltage swell occurs. Based on the output voltages, the system frequency is reduced, so that the output voltage is also reduced. By this the voltage swell is compensated in the system.

\subsection{Simulation Results and Discussions}

Figure 6 shows the current and voltage waveforms mitigated due to voltage sag and swell. When the load increases, the load voltage decreases causing voltage sag. It is determined from the current and voltage values of the system and accordingly the frequency of the inverter is increased and so the voltage is restored. Swell occurs when the load decreases. At that time, the frequency is reduced to restore the required voltage. These are evidenced from the waveforms depicted in Figure 6.

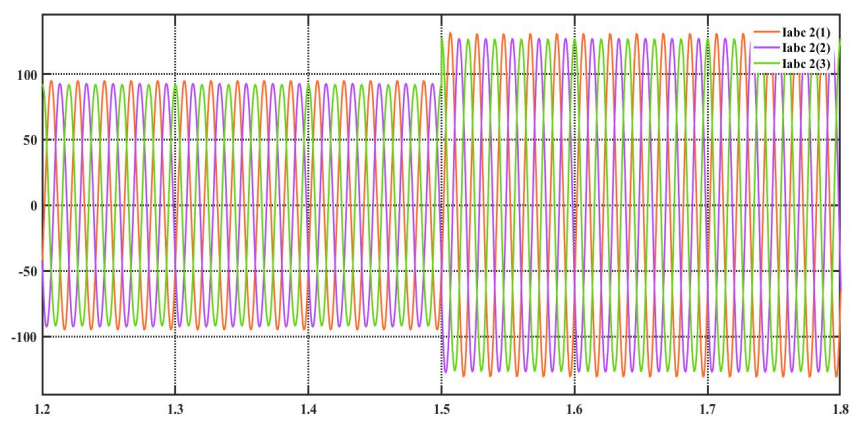

(i) Current Waveform

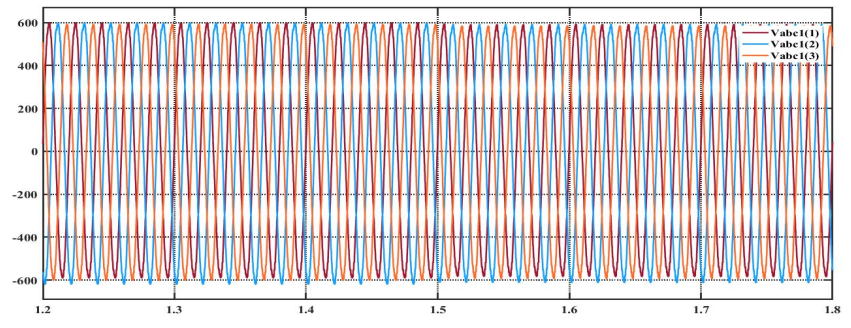

(ii) Voltage Waveform 
(a) Sag Condition

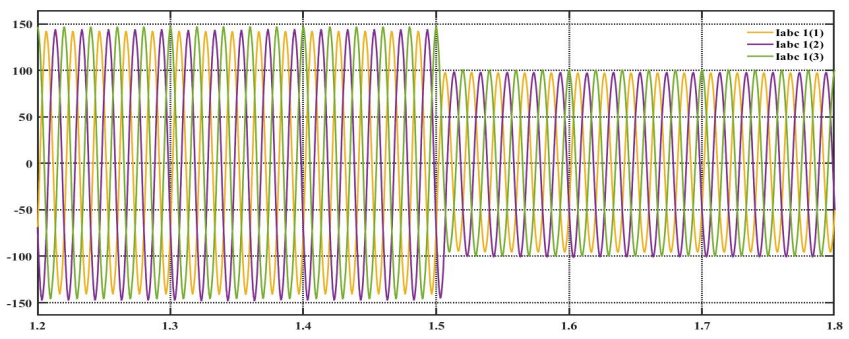

(i) Current Waveform

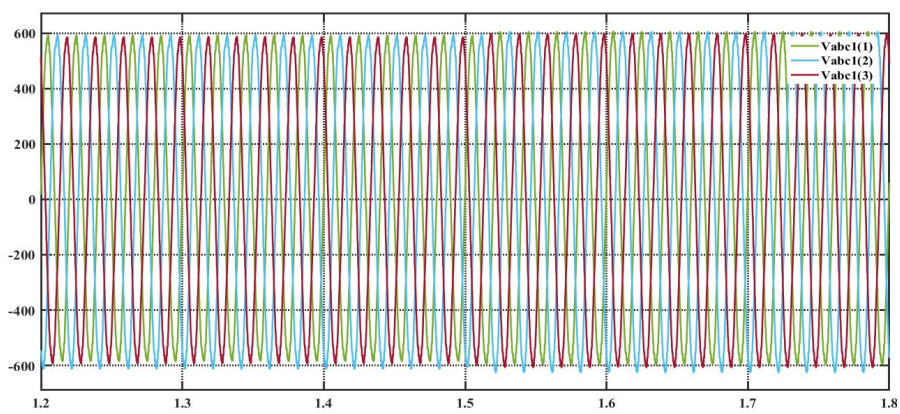

(ii) Voltage Waveform

(b) Swell Condition

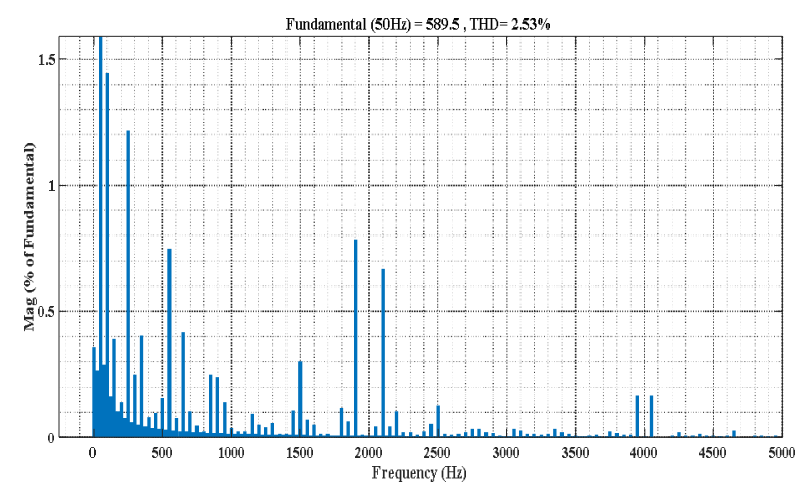

(i) Voltage THD

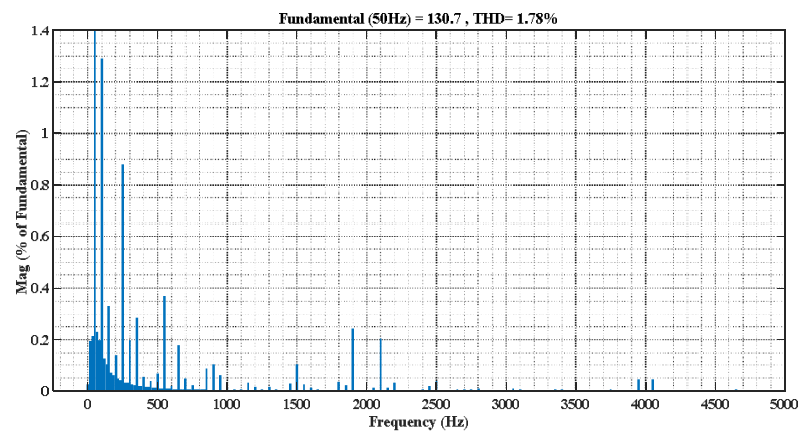

(ii) Current THD

(c) THD Values

Figure 6: Simulation Results

The THD values of the system are measured at fundamental power frequency of $50 \mathrm{~Hz}$ and $50 \%$ load conditions. The voltage and current THD functions are found to be $2.53 \%$ and $1.78 \%$.

\section{CONCLUSION}

A fuzzy logic driven novel solid state transformer with dual winding transformer fed by dual active bridge has been proposed. The MATLAB/Simulink model of the proposed system has been developed and the simulation results have been analyzed. The simulation results shows that the proposed SST system mitigated effectively the voltage sag and swell conditions. The THD analysis at the fundamental frequency was found to be $2.53 \%$ for voltage and $1.78 \%$ for current. The THD values are within the standards of less than $4 \%$. These results evident that the proposed fuzzy driven SST with dual winding transformer can be effectively used for power quality enhancements.

\section{REFERENCES}

1. Kheraluwala, M.N.; Gascoigne, R.W.; Divan, D.M.; Baumann, E.D., "Performance characterization of a high-power dual active bridge DC-to-DC converter," Industry Applications, IEEE Transactions on, vol.28, no.6, pp.1294-1301, Nov/Dec 1992. https://doi.org/10.1109/28.175280

2. Hao Chen, Anish Prasi and Deepak Divan, "Dyna-C: A Minimal Topology for Bi-Directional Solid State Transformers". IEEE Transactions on Power Electronics Vol. 20, No. 5, 2015.

3. Biao Zhao, Qiang Song, Wenhua Liu and Yandong Sun, "Overview of Dual-Active-Bridge Isolated Bidirectional DC-DC Converter for High-Frequency-Link Power-Conversion System", IEEE Transactions on Power Electronics, Vol.29, No.8, 2016.

4. Abdul Manna, S Imran Syed, Vinod Khadkikar, "Replacing the Grid Interface Transformer in Wind Energy Conversion System With Solid State Transformer", IEEE Transactions on Power Systems, Vol. 32, No. 3, 2017., pp. $2152-2160$.

5. Patrick Himmelmann and Marc Hiller, "Solid-state transformer based on modular multilevel converters", The Journal of Engineering, Vol. 2019, No. 17, 2019. https://doi.org/10.1049/joe.2018.8023

6. Juliano De O pAcheco, Dalton DE A Honorio and Demercil De S Oliveria, "An AC-DC Isolated MMC-Based Structure Suitable for MV SST Traction Applications", IEEE access, vol. 7, 2019.

7. Jiepin Zhang, Jiqnqiang Liu, Jingxi Yang, Nan Zhaao, Yang Wang and Trillion Q Zheng, "A Modified DC Power Electronic Transformer Based on Series Connection of Full-Bridge Converters", IEEE transactions on power electronics, vol. 34, no. 3, 2019. https://doi.org/10.1109/TPEL.2018.2842728

8. Aaron Don M. Africa, Patrick Bernard T. Arevalo, Arsenic S. Publico, Mharela Angela A. Tan, "Fuzzy Logic Control System with Gaussian Membership Functions", International Journal of Emerging Trends in 
Saju N et al., International Journal of Emerging Trends in Engineering Research, 8(8), August 2020, 4097 - 4101

Engineering Research, Vol. 7, No. 9 Sep-2019, pp. 328-332.

https://doi.org/10.30534/ijeter/2019/16792019

9. M Siva Kumar, Syed Inthiyaz, M Aditya, P Rupanjani, B Aravind , M Mukesh, Sanath Kumar Tulasi, "Implementation of GDI Logic for Power Efficient SRAM Cell with Dynamic Threshold Voltage Levels", International Journal of Emerging Trends in Engineering Research, Vol. 7, No. 12, Dec-2019, pp.902-906.

https://doi.org/10.30534/ijeter/2019/287122019 